\title{
Development and Performance of a Web-Based Tool to Adjust Urine Toxicology Testing Frequency: Retrospective Study
}

Kenneth B Chapman ${ }^{1,2}$, MD; Martijn M Pas ${ }^{2,3}$, BSc; Diana Abrar ${ }^{2,3}, \mathrm{BSc}$; Wesley Day ${ }^{2}$, BSc; Kris C Vissers ${ }^{4}$, MD, $\mathrm{PhD}$; Noud van Helmond ${ }^{2,5}$, MD

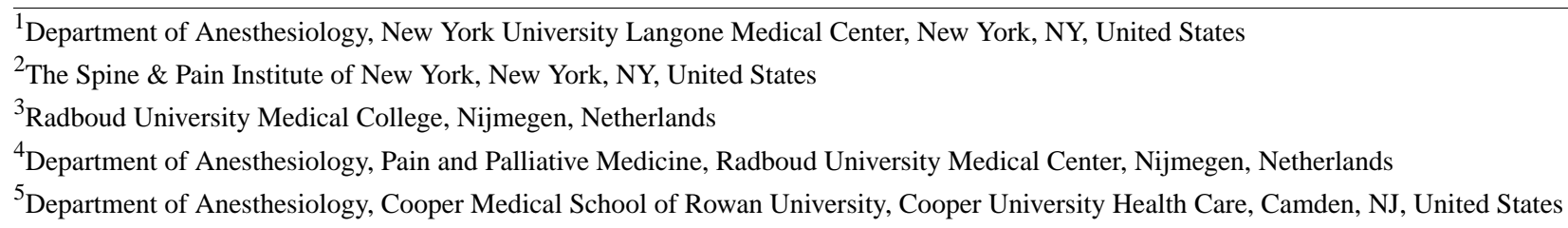

Corresponding Author:

Kenneth B Chapman, MD

Department of Anesthesiology

New York University Langone Medical Center

550 First Avenue

New York, NY,

United States

Phone: 12122635072

Email: Kenneth.Chapman@nyumc.org

\section{Abstract}

Background: Several pain management guidelines recommend regular urine drug testing (UDT) in patients who are being treated with chronic opioid analgesic therapy (COAT) to monitor compliance and improve safety. Guidelines also recommend more frequent testing in patients who are at high risk of adverse events related to COAT; however, there is no consensus on how to identify high-risk patients or on the testing frequency that should be used. Using previously described clinical risk factors for UDT results that are inconsistent with the prescribed COAT, we developed a web-based tool to adjust drug testing frequency in patients treated with COAT.

Objective: The objective of this study was to evaluate a risk stratification tool, the UDT Randomizer, to adjust UDT frequency in patients treated with COAT.

Methods: Patients were stratified using an algorithm based on readily available clinical risk factors into categories of presumed low, moderate, high, and high+ risk of presenting with UDT results inconsistent with the prescribed COAT. The algorithm was integrated in a website to facilitate adoption across practice sites. To test the performance of this algorithm, we performed a retrospective analysis of patients treated with COAT between June 2016 and June 2017. The primary outcome was compliance with the prescribed COAT as defined by UDT results consistent with the prescribed COAT.

Results: 979 drug tests (867 UDT, 88.6\%; 112 oral fluid testing, 11.4\%) were performed in 320 patients. An inconsistent drug test result was registered in 76/979 tests $(7.8 \%)$. The incidences of inconsistent test results across the risk tool categories were $7 / 160(4.4 \%)$ in the low risk category, $32 / 349(9.2 \%)$ in the moderate risk category, $28 / 338(8.3 \%)$ in the high risk category, and $9 / 132(6.8 \%)$ in the high+ risk category. Generalized estimating equation analysis demonstrated that the moderate risk (odds ratio (OR) 2.1, 95\% CI 0.9-5.0; $P=.10$ ), high risk (OR 2.0, 95\% CI 0.8-5.0; $P=.14)$, and high risk+ (OR 2.0, 95\% CI 0.7-5.6; $P=.20)$ categories were associated with a nonsignificantly increased risk of inconsistency vs the low risk category.

Conclusions: The developed tool stratified patients during individual visits into risk categories of presenting with drug testing results inconsistent with the prescribed COAT; the higher risk categories showed nonsignificantly higher risk compared to the low risk category. Further development of the tool with additional risk factors in a larger cohort may further clarify and enhance its performance.

(JMIR Med Inform 2020;8(4):e16069) doi: 10.2196/16069 


\section{KEYWORDS}

Urine drug testing; Opioid therapy; Chronic noncancer pain

\section{Introduction}

Despite a decline in opioid prescriptions since the height of the opioid crisis in the United States, the use of opioids for the treatment of chronic pain continues to be common, particularly among primary care physicians [1]. Chronic opioid analgesic treatment (COAT) may be associated with the development of opioid use disorders in a subset of patients [2]. To improve the safety of COAT, guidelines recommend a reduction in opioid dosage for patients prescribed high-dose COAT and monitoring of compliance with the prescribed COAT regimen [3-8].

Urine drug testing (UDT) has been suggested by several guidelines as a method to observe compliance with the prescribed therapy in patients treated with COAT [3-8]. Guidelines state that UDT should be performed at the initiation of opioid treatment [7], at least once a year for patients prescribed COAT [7], and more often for patients at higher risk of adverse consequences from COAT [6]. However, identification of high-risk patients with currently available tools may not be reliable [7]. In the absence of effective tools to identify high-risk patients, some pain physicians have advocated requiring UDT of patients every visit to increase safety through early detection of inconsistent results [9]. As a result, insurance companies have noticed a sharp increase in UDT expenditures [10] and have demanded that physicians justify performing UDT in individual patients to reduce costs [11].

Several readily available treatment-related factors are known to be associated with an increased risk of UDT results that are inconsistent with the prescribed COAT. These factors include younger age [12,13], concomitant use of a benzodiazepine [14], a history of UDT results that are inconsistent with the prescribed COAT [15], and a higher prescribed daily morphine equivalent dose [13]. We created a web-based clinical tool that uses these factors to adjust the frequency of UDT administered in a chronic noncancer pain population. The aim of this retrospective study was to validate our stratification algorithm by comparing the risk allocation of the tool and the results of drug testing over the course of 12 months.

\section{Methods}

\section{Inclusion Criteria}

This study was conducted in a private interventional pain management institute with 7 specialists across 4 different locations in the New York City area. We retrospectively identified patients without cancer who had chronic pain that was treated with COAT by reviewing charts between June 1, 2016 and July 1, 2016. Visits from the 12 months following the initial visit in June 2016 were reviewed for UDT results and for their consistency with the prescribed opioid therapy. The UDT Randomizer risk categories associated with each UDT result were also obtained. The UDT Randomizer risk stratification tool was implemented as part of the standard of clinical care at the institute in March 2016 and had thus been part of normal practice for some time prior to the inclusion date. Inclusion criteria for the study were age $\geq 18$ years and treatment with opioids (extended release or immediate release) for more than 12 consecutive weeks at the start of the retrospective inclusion period. We allowed for a gap period of up to 4 weeks in opioid treatment. The underlying cause of chronic pain was retrieved from each patient's medical record, and patients with pain due to cancer were excluded. The Staten Island University Institutional Review Board approved this study (study number: 18-0906-SIUHN) and waived the requirement to obtain informed consent for this retrospective study.

\section{UDT Risk Stratification and Testing Frequency With the UDT Randomizer Tool}

The developed stratification tool is depicted in Figure 1. Patients were assigned to a presumed risk group (low, moderate, high, or high+) based on established risk factors for UDT results inconsistent with the prescribed COAT. Patients with a history of drug testing inconsistent with the prescribed COAT are flagged in our electronic medical records, and this flag remains for the duration of treatment in our practice. Drug testing results inconsistent with the prescribed COAT may serve as an early warning of adverse outcomes of COAT [9]; therefore, we focused on developing a tool to effectively detect results inconsistent with the prescribed COAT. The risk allocation was initially based on the daily morphine equivalent dose prescribed ( $<40,40-100$, or $>100$ milligrams). The web tool incorporates a morphine equivalent dose calculator to facilitate this step. This calculator is based on a previously developed calculator [16] that was based on American Pain Society guidelines [17] and on several reviews regarding equianalgesic dosing [18-20]. When 1 or more of the additional risk factors are present (age $<45$ years, concomitant benzodiazepine use, or a history of drug testing results inconsistent with the prescribed COAT), the patient is escalated by 1 risk category (Figure 2). 
Figure 1. Screenshots of the UDT Randomizer tool prior to the selection of risk factors (A) and after the selection of risk factors (B). The recommendation to perform testing is "Yes" in this case.

A

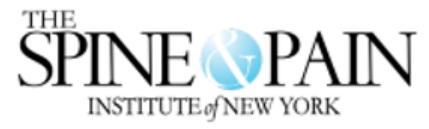

B

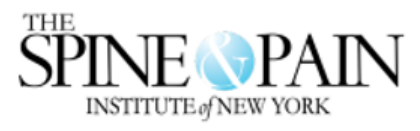

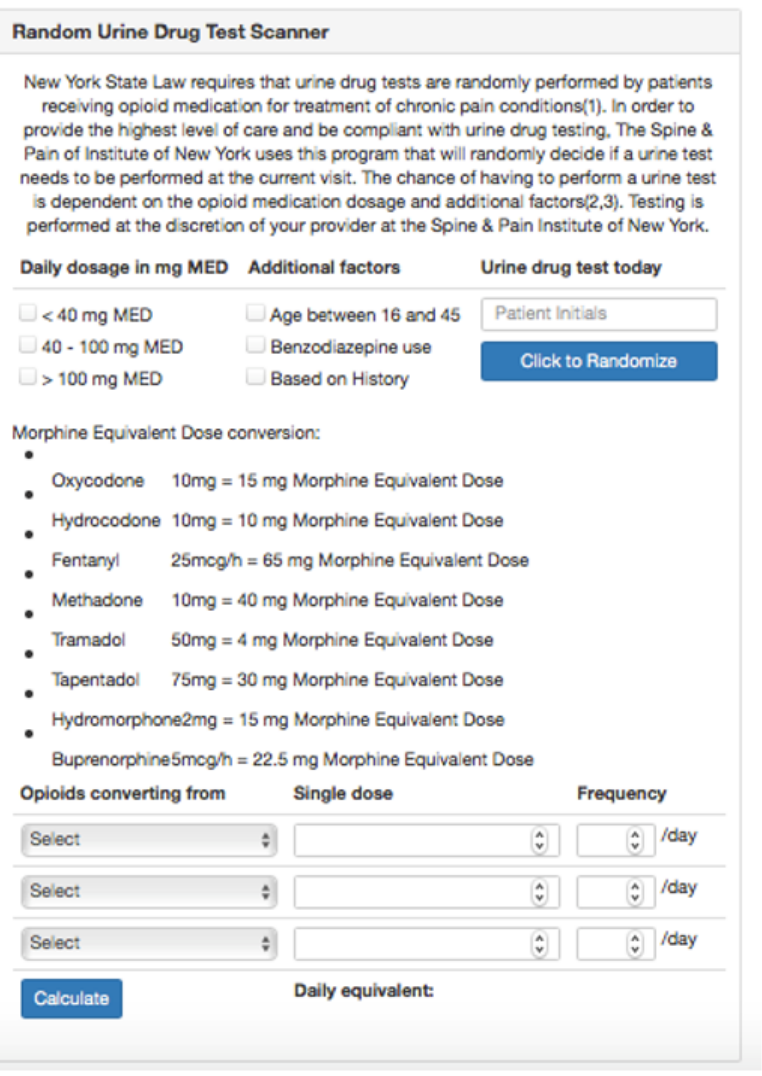

Patients allocated to the low, moderate, high, and high+ risk categories are randomly requested to undergo UDT at frequencies of $25 \%, 33 \%, 50 \%$, and $60 \%$, respectively. It is important to stress that the chance of being requested to participate in UDT is thus not random but is rather random with a certain pre-set probability. We arrived at the testing

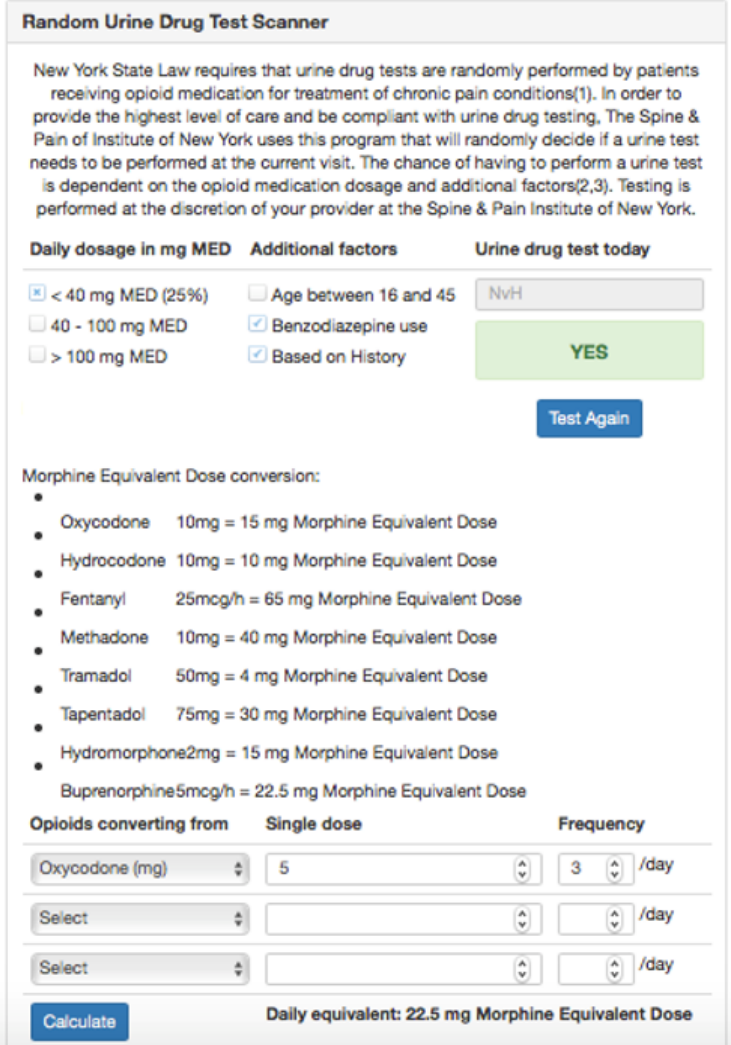

frequencies through evaluation of the Washington State Agency Medical Directors' Group Interagency Guideline and American Academy of Pain Medicine recommendations on frequency of testing $[6,21]$. We estimated that we would be able to achieve the recommended testing frequencies by choosing these set frequencies for the UDT Randomizer.

Figure 2. Risk category allocation and the corresponding pre-set chance that the UDT Randomizer tool will request UDT during a patient visit.

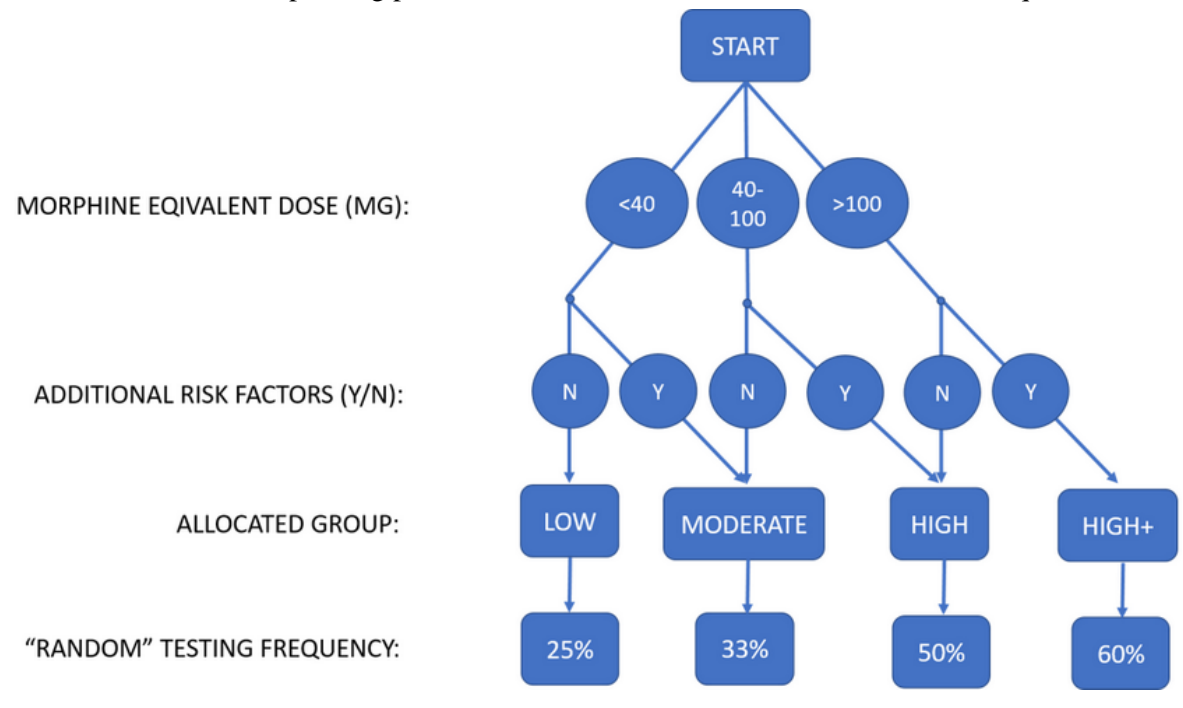




\section{Primary Outcome}

The primary outcome was compliance with the prescribed opioid therapy. This was assessed by the drug test results and their consistency with the prescribed opioids over the study period. A drug test result was considered to be consistent if it was positive for the prescribed opioid or its metabolites and was negative for other opioids, their metabolites, or illicit substances. A drug test result was considered to be inconsistent if it was negative for the prescribed opioid or its metabolites or if it was positive for nonprescribed opioids, their metabolites, or illicit substances. Consistent with recent Centers for Disease Control and Prevention (CDC) guidance [7], we did not take into account the results of testing for tetrahydrocannabinol (THC) when determining if a UDT was consistent or inconsistent with the prescribed therapy.

\section{Drug Testing}

Urine toxicology testing was performed by an independent laboratory using liquid chromatography tandem mass spectrometry (Triple Quad 4500 MD, AB Sciex). If a patient was not able to provide a urine sample, oral fluid was collected for analysis. Both urine and oral fluid samples were examined for the presence of prescribed opioids, benzodiazepines, illicit drugs, and their respective metabolites. Chromatographic tests are specific and are not susceptible to cross-reactions; thus, false positive results are rare [22]. The detection window is substantially shorter for oral fluid testing vs urine testing (eg, morphine is detectable 2-5 days after use in urine vs 1-36 hours in oral fluid [23]). When a drug is within the detection windows for both UDT and oral fluid testing, the detection rates are believed to be similar [24].

\section{Data Retrieval}

Patient demographics, diagnoses, prescribed medications, and drug testing results were collected retrospectively from the patients' medical records. Pain diagnoses were grouped into categories of lower back pain; cervical pain; arthritis, joint, and muscle pain; and other pain. We retrieved information from all visits in the 12-month period following the initial included visit in June 2016. Because the data analysis was conducted at the individual visit level (see the Data and Statistical Analysis section), we included data regardless of whether the patients remained in our care for the full 12-month period.

\section{Data and Statistical Analysis}

Demographics and clinical data are presented as mean (SD) or as $\mathrm{n}(\%)$. To assess the uptake of the UDT Randomizer tool, we analyzed how often the tool was used during the first visit for each patient in the study period. We also assessed how often the tool's recommendation (Yes or No for UDT) was followed at that visit. Additionally, we assessed how often UDT testing was ordered without recommendation by the tool over the course of the entire study period as well as how often the UDT testing recommended by the tool was ignored by providers over the course of the entire study period. We performed generalized estimating equations (GEE) analysis with the factors "risk category" and "visit" to assess if the assigned risk category was related to the consistency of drug testing results with the prescribed COAT using all tests and risk assignments in the 12-month study period. We used GEE to account for repeated testing in the same patient. To assess our assumption that there is no association between marijuana use and drug testing results inconsistent with the prescribed COAT, we performed GEE analysis with THC status on drug testing as a factor for the consistency of drug testing results with the prescribed COAT as the outcome. The results of the analyses are presented as odds ratios (ORs) with $95 \%$ confidence intervals and the corresponding $P$ values. Statistical significance was set at $P<.05$. The software package SPSS version 24 (IBM Corporation) was used for all statistical analyses.

\section{Results}

\section{Study Population}

The study population consisted of 320 patients, of whom 172 $(53.8 \%)$ were female and $148(46.3 \%)$ were male (Table 1$)$. Most of the patients' diagnoses $(214 / 320,66.9 \%)$ were related to spinal pain.

Table 1. Demographic and treatment characteristics of the patients included in the study.

\begin{tabular}{ll}
\hline Characteristic & Patients (N=320) \\
\hline $\begin{array}{l}\text { Age, mean (SD) } \\
\text { Gender, } \mathbf{n}(\boldsymbol{\%})\end{array}$ & $57(12)$ \\
$\quad$ Male & $148(46.3)$ \\
$\quad$ Female & $172(53.8)$ \\
Pain diagnosis, $\mathbf{n}(\boldsymbol{\%})$ & \\
$\quad$ Lower back & $214(66.9)$ \\
$\quad$ Cervical & $74(23.1)$ \\
$\quad$ Arthritis, joint, and muscle & $22(7.9)$ \\
$\quad$ Other & $10(3.1)$ \\
Prescribed opioid dosage in morphine milligram equivalents/day, mean (SD) & $70(66)$ \\
Concomitant use of benzodiazepines, n (\%) & $91(28.4)$ \\
\hline
\end{tabular}

${ }^{\text {a }}$ Patients in this category were diagnosed with abdominal pain, endometriosis, pelvic pain, fibromyalgia, phantom limb pain, or trigeminal neuralgia. 
We found that the uptake of the UDT Randomizer tool was high at the first visit in the study period: it was used in $318 / 320$ patients $(99.3 \%)$, and its recommendation regarding testing was followed 314 of the 318 times it was used $(99.7 \%)$. Over the course of the entire 12-month study period, the recommendation of the tool to test ("Yes") was followed in 945/964 (98.0\%) of visits. Over the 12-month period, 34 tests were performed contrary to the tool's guidance to not perform a test.

\section{Primary Outcome: Drug Testing Consistency with the Prescribed COAT}

A total of 979 drug tests were performed in the study population over the retrospective 12-month duration of the study. Of the performed tests, $867 / 979(88.6 \%)$ were urine drug tests, whereas $112(11.4 \%)$ were oral fluid tests. All patients provided at least 1 drug test during the follow-up period. Inconsistent drug test results were registered for $76 / 979$ tests $(7.8 \%)$ in 52/320 patients $(16.3 \%)$ during this period. The incidence of inconsistent test results across the UDT Randomizer tool risk categories varied from $4.4 \%$ (low risk) to $9.2 \%$ (moderate risk), $8.3 \%$ (high risk), and $6.8 \%$ (high+ risk; Table 2).

Of the 979 drug tests, 119 (12.2\%) were positive for THC, and the positive tests were obtained in $25 / 320$ patients $(7.8 \%)$. GEE analysis with the risk factors "THC" and "visit" did not demonstrate significantly higher risk of drug testing inconsistent with the prescribed COAT when a positive test for THC was also present (OR 1.3, 95\% CI 0.6-3.0; $P=.48$ ).

\section{Relationships Between the Risk Tool Categories and the Consistency of UDT Results With the Prescribed COAT}

GEE analysis revealed that tests in the moderate, high, and high+ risk categories were associated with a nonsignificantly higher risk of inconsistency with the prescribed COAT (Table $3)$.

Because the ORs appeared to be homogenous among the moderate, high, and high+ categories, we performed a secondary GEE analysis to explore the value of stratifying patients into only 2 risk categories as a potential next step in the development of the UDT Randomizer tool. We combined the previous moderate, high, and high+ categories into one high risk category. The performance of this stratification with regard to the consistency of drug testing with the prescribed opioid therapy was found to be similar to that of the individual categories in the initial 4-category system (OR of high vs low: $2.0,95 \%$ CI 0.9-4.7; $P=.09$ ).

Additionally, we explored whether a lower cutoff point of 20 daily morphine milligram equivalents prescribed could improve discrimination by the UDT Randomizer tool. GEE analysis indicated that this cutoff did not perform better than the previous 2-risk category stratification (OR of high vs low: $1.4,95 \% \mathrm{CI}$ $0.4-4.8 ; P=.60)$.

Table 2. Consistency of drug tests with the prescribed opioid therapy in the 4 risk categories of the UDT Randomizer tool.

\begin{tabular}{lllll}
\hline Result & $\begin{array}{l}\text { Risk category } \\
\text { Low }(\mathrm{n}=160)\end{array}$ & Moderate $(\mathrm{n}=349)$ & High $(\mathrm{n}=338)$ & High+ $(\mathrm{n}=132)$ \\
\hline $\begin{array}{l}\text { Drug test result, } \mathbf{n}(\boldsymbol{\%}) \\
\quad \text { Consistent }\end{array}$ & $153(95.6)$ & $317(90.8)$ & $310(91.7)$ & $123(93.2)$ \\
$\quad \begin{array}{l}\text { Inconsistent } \\
\text { Inconsistency of result, } \mathbf{n}(\boldsymbol{\%})\end{array}$ & $7(4.4)$ & $32(9.2)$ & $28(8.3)$ & $9(6.8)$ \\
$\quad \begin{array}{l}\text { Negative for prescribed opioid } \\
\quad \text { Positive for unprescribed opioid }\end{array}$ & $3(1.9)$ & $13(3.7)$ & $12(42.9)$ & $3(33.3)$ \\
$\quad 3(1.9)$ & $15(4.3)$ & $12(42.9)$ & $6(66.7)$ \\
\hline
\end{tabular}

Table 3. Generalized estimating equations analysis of the influence of the UDT Randomizer risk category on the consistency of drug testing with the prescribed opioid therapy.

\begin{tabular}{lll}
\hline Risk category & $\mathrm{OR}^{\mathrm{a}}(95 \% \mathrm{CI})$ & $P$ value \\
\hline Low & Reference & Reference \\
Moderate & $2.1(0.9-5.0)$ & .10 \\
High & $2.0(0.8-5.0)$ & .14 \\
High+ & $2.0(0.7-5.6)$ & .20 \\
\hline
\end{tabular}

${ }^{\mathrm{a}} \mathrm{OR}$ : odds ratio 


\section{Discussion}

\section{Principal Findings}

The aim of this study was to assess a risk stratification algorithm we developed to adjust the drug testing frequency in patients being treated with COAT. The main findings are that the overall inconsistency of drug testing results with the prescribed COAT was low and that tests in the predefined moderate, high, and high+ risk categories had a nonsignificantly higher risk of being inconsistent with the prescribed COAT.

Based on available evidence, UDT has been suggested by several guidelines as a method to observe compliance with the prescribed therapy in patients treated with COAT [3-8]. However, none of these guidelines provide practical advice on the frequency of testing that should be employed. In the absence of such guidance, some pain physicians have adopted the policy of performing UDT virtually every visit to promote safety and to ensure compliance with regulations, leading to subsequent concerns of overutilization of UDT [10] and regulatory fines [25]. At the same time, a proportion of physicians undertest their patients, leading to risk that opioid-related adverse events will not be prevented [26]. Another common approach to testing is a standardized testing interval of every 3-4 months, which allows patients to prepare for upcoming UDT [15]. Appropriate patient selection for UDT would help limit overall expenses while maintaining a safe prescription environment. Prior tools that have been developed to estimate the risk of opioid abuse include the Screener and Opioid Assessment for Patients in Pain-Revised [27,28], the Current Opioid Misuse Measure [29], the Screening Instrument for Substance Abuse Potential [30], the Opioid Risk Tool [31] and the Diagnostic, Intractability, Risk, Efficacy [32] tool. These tools consist of 5-24 questions regarding behavioral factors and family history that impose a greater risk of opioid use disorders. These tools may require a significant time investment from both the patient and the pain physician and are dependent on the truthful responses of the patient. In the context of opioid use disorders, data generally show that such self-reporting is unreliable [33]. The urine toxicology tool we developed avoids self-reporting, and it incorporates only demographic and treatment-related factors that are readily available from the patient's electronic medical record. Because the randomizer uses an algorithm based on treatment-related factors, the decision whether to perform UDT is not dependent on a direct decision made by a health care provider, which adds subjectivity to the decision process [34], and the algorithm returns randomization based solely on probability. Furthermore, taking the provider factor out of the equation may have a positive effect on the patient-physician relationship, as the physician is removed from the decision of whether UDT should be performed [7]. The tool can be utilized by any health care professional assisting the physician in the care of the patient, since all risk factors are readily available from the medical record. The presented approach avoids a routine schedule for testing (eg, every 3 or 4 months), which may be amenable to manipulation by patients who are prone to opioid misuse $[7,15]$. The results of this study indicate that at present, the tool cannot identify patients who are at significantly higher risk of presenting with testing results inconsistent with their prescribed COAT. There were nonsignificant differences in inconsistent UDT results between the moderate, high, and high+ categories and the low risk category. It is possible that this study is not sufficiently powered to detect differences between these groups, given the overall low incidence of inconsistent UDT results. The homogeneity of the inconsistency rates in the moderate, high, and high + categories suggests that development of the tool should focus on combining the current moderate, high, and high+ categories while incorporating other risk factors to effectively distinguish between higher risk and lower risk patients.

The overall level of observed consistency of the UDT results with the prescribed opioid therapy was high in the present study $(83.7 \%)$. This percentage is similar to the percentage reported in a recent study by Knezevic et al [15], in which $77.2 \%$ of the observed study population was found to present with consistent UDT results. In earlier studies, these rates were found to be much lower $(25 \%-56 \%)$ [12,35,36]. These differences may be due to increased attention to compliance with COAT and UDT among physicians in more recent studies, differences in the studied populations, or differences in the definition of a "consistent result" of UDT. In our sample, 25 patients were found to test positive for THC; however, we did not consider a positive UDT result for THC to be proof of illicit drug use. In the present study, there was no association between marijuana use and UDT results inconsistent with the prescribed COAT. In the most recent CDC opioid prescription guidelines, experts noted that it may not be useful to test for THC on UDT because it is unclear if a positive test for THC should affect patient management [7]. Earlier studies reported associations between marijuana use in chronic opioid patients and present and future opioid misuse [37]. Research in twins has suggested that early-onset marijuana use is a risk factor for developing more severe and pervasive drug use disorders [38]. Currently, fewer people in the United States perceive marijuana to be harmful compared to a decade ago [39]. Medical marijuana has been introduced in 33 states (including New York and New Jersey), and 11 states allow recreational marijuana use. In states where marijuana is legalized for medical use, chronic pain is one of the approved indications [40], and most persons acquiring medical marijuana do so for pain management [41]. It has been suggested that medical marijuana legalization reduces overall opioid prescribing and high-risk opioid use [42] by providing an alternative treatment for chronic pain. It has been suggested that medical marijuana and recreational marijuana use have opposite effects on overall opioid use and opioid misuse (ie recreational marijuana increases opioid use and opioid misuse [43]), although a recent analysis of states that legalized recreational marijuana found no increases in opioid prescriptions [44].

\section{Strengths and Limitations}

This was a retrospective study conducted at a single institution. A strength of the study was the prospective effective implementation of the intervention in the institution prior to the evaluation in this study.

Drug testing results inconsistent with prescribed COAT have been suggested to serve as an early warning of adverse outcomes 
of COAT [9]; therefore, we focused on developing a tool to effectively detect inconsistent results. However, the ultimate relationship between the implementation of UDT in the management of patients treated with COAT and long-term adverse events of COAT is not well established at present [7], even though its value in improving safety is assumed in several guidelines [3-8].

\section{Conclusion}

The developed tool stratified patients during individual visits into risk categories of presenting with drug testing results inconsistent with the prescribed COAT; the higher risk categories showed nonsignificantly higher risk than the low risk category. Further development of this tool with additional risk factors in a larger cohort may further clarify and enhance its performance.

\section{Acknowledgments}

We thank Craig Hartrick MD, Director of Anesthesiology Research and Director of Pain Services at Beaumont Hospitals/Oakland University, for his input throughout the course of this work and for commenting on a draft of this paper. This work received no specific grant from any funding agency in the public, commercial, or not-for-profit sectors.

\section{Authors' Contributions}

KBC helped design the study, summarize previous related work, and draft the manuscript. MMP helped acquire the data, perform literature searches, summarize previous related work, and edit and revise the manuscript. DA and WD helped acquire the data and edit and revise the manuscript. KCV helped edit and revise the manuscript. NvH helped design the study, analyze the data, prepare the figures, and edit and revise the manuscript.

\section{Conflicts of Interest}

None declared.

\section{References}

1. Tong ST, Hochheimer CJ, Brooks EM, Sabo RT, Jiang V, Day T, et al. Chronic Opioid Prescribing in Primary Care: Factors and Perspectives. Ann Fam Med 2019 May;17(3):200-206 [FREE Full text] [doi: 10.1370/afm.2357] [Medline: 31085523]

2. Edlund MJ, Martin BC, Russo JE, DeVries A, Braden JB, Sullivan MD. The role of opioid prescription in incident opioid abuse and dependence among individuals with chronic noncancer pain: the role of opioid prescription. Clin J Pain 2014 Jul;30(7):557-564 [FREE Full text] [doi: 10.1097/AJP.0000000000000021] [Medline: 24281273]

3. Chou R, Fanciullo GJ, Fine PG, Adler JA, Ballantyne JC, Davies P, American Pain Society-American Academy of Pain Medicine Opioids Guidelines Panel. Clinical guidelines for the use of chronic opioid therapy in chronic noncancer pain. $\mathbf{J}$ Pain 2009 Mar;10(2):113-130 [FREE Full text] [doi: 10.1016/j.jpain.2008.10.008] [Medline: 19187889]

4. VA/DOD Clinical Practice Guideline for Management of Opioid Therapy for Chronic Pain. Washington, DC: Department of Veterans Affairs and Department of Defense; 2010. URL: https://www.healthquality.va.gov/guidelines/Pain/cot/ VADoDOTCPG022717.pdf [accessed 2020-04-17]

5. Utah Clinical Guidelines on Prescribing Opioids for Treatment of Pain. Salt Lake City, UT: Utah Department of Health; 2009. URL: http://www.health.utah.gov/vipp/pdf/RxDrugs/UtahClinicalGuidelinesOnPrescribing.pdf [accessed 2020-04-17]

6. Interagency Guideline on Prescribing Opioids for Pain. Seattle, WA: Washington State Agency Medical Directors Group; 2015. URL: http://www.agencymeddirectors.wa.gov/Files/2015AMDGOpioidGuideline.pdf [accessed 2020-04-17]

7. Dowell D, Haegerich TM, Chou R. CDC Guideline for Prescribing Opioids for Chronic Pain — United States, 2016. MMWR Recomm. Rep 2016 Mar 18;65(1):1-49. [doi: 10.15585/mmwr.rr6501e1]

8. Manchikanti L, Kaye AM, Knezevic NN, McAnally H, Slavin K, Trescot AM, et al. Responsible, Safe, and Effective Prescription of Opioids for Chronic Non-Cancer Pain: American Society of Interventional Pain Physicians (ASIPP) Guidelines. Pain Physician 2017 Feb;20(2S):S3-S92 [FREE Full text] [Medline: 28226332]

9. DiBenedetto DJ, Wawrzyniak KM, Schatman ME, Shapiro H, Kulich RJ. Increased frequency of urine drug testing in chronic opioid therapy: rationale for strategies for enhancing patient adherence and safety. J Pain Res 2019;12:2239-2246 [FREE Full text] [doi: 10.2147/JPR.S213536] [Medline: 31413622]

10. Kaye AD, Marshall ZJ, Lambert SM, Trescot AM, Prabhakar A, Elhassan AO, et al. Ethical perspectives on urine drug screening for pain physicians. Pain Physician 2014;17(5):E559-E564 [FREE Full text] [Medline: 25247905]

11. Weaver CA. Lab Nears Settlement Over Pricey Medicare Drug Tests. The Wall Street Journal 2015 Jun 14.

12. Michna E, Jamison RN, Pham L, Ross EL, Janfaza D, Nedeljkovic SS, et al. Urine toxicology screening among chronic pain patients on opioid therapy: frequency and predictability of abnormal findings. Clin J Pain 2007 Mar;23(2):173-179. [doi: 10.1097/AJP.0b013e31802b4f95] [Medline: 17237667]

13. Turner JA, Saunders K, Shortreed SM, LeResche L, Riddell K, Rapp SE, et al. Chronic opioid therapy urine drug testing in primary care: prevalence and predictors of aberrant results. J Gen Intern Med 2014 Dec;29(12):1663-1671 [FREE Full text] [doi: 10.1007/s11606-014-3010-y] [Medline: 25217208] 
14. McClure FL, Niles JK, Kaufman HW, Gudin J. Concurrent Use of Opioids and Benzodiazepines: Evaluation of Prescription Drug Monitoring by a United States Laboratory. J Addict Med 2017;11(6):420-426 [FREE Full text] [doi: 10.1097/ADM.0000000000000354] [Medline: 28953504]

15. Knezevic NN, Khan OM, Beiranvand A, Candido KD. Repeated Quantitative Urine Toxicology Analysis May Improve Chronic Pain Patient Compliance with Opioid Therapy. Pain Physician 2017 Feb;20(2S):S135-S145 [FREE Full text] [Medline: 28226335]

16. ClinCalc.com. 2019. Equivalent Opioid Calculator URL: https://clincalc.com/Opioids/ [accessed 2019-08-28]

17. American Pain Society. Principles of Analgesic Use in the Treatment of Acute Pain and Cancer Pain, 6th Edition. Glenview, IL: American Pain Society; 2008.

18. Anderson R, Saiers JH, Abram S, Schlicht C. Accuracy in equianalgesic dosing. conversion dilemmas. J Pain Symptom Manage 2001 May;21(5):397-406 [FREE Full text] [doi: 10.1016/s0885-3924(01)00271-8] [Medline: 11369161$]$

19. Pereira J, Lawlor P, Vigano A, Dorgan M, Bruera E. Equianalgesic dose ratios for opioids. a critical review and proposals for long-term dosing. J Pain Symptom Manage 2001 Aug;22(2):672-687 [FREE Full text] [doi: 10.1016/s0885-3924(01)00294-9] [Medline: 11495714]

20. Patanwala AE, Duby J, Waters D, Erstad BL. Opioid conversions in acute care. Ann Pharmacother 2007 Feb;41(2):255-266. [doi: 10.1345/aph.1H421] [Medline: 17299011]

21. Peppin JF, Passik SD, Couto JE, Fine PG, Christo PJ, Argoff C, et al. Recommendations for urine drug monitoring as a component of opioid therapy in the treatment of chronic pain. Pain Med 2012 Jul;13(7):886-896. [doi: 10.1111/j.1526-4637.2012.01414.x] [Medline: 22694154]

22. Hadland SE, Levy S. Objective Testing: Urine and Other Drug Tests. Child Adolesc Psychiatr Clin N Am 2016 Jul;25(3):549-565 [FREE Full text] [doi: 10.1016/j.chc.2016.02.005] [Medline: 27338974]

23. National Center on Substance Abuse and Child Welfare, Substance Abuse Mental Health Services Administration. Drug Testing Practice Guidelines. 2015. URL: https://ncsacw.samhsa.gov/files/IA Drug Testing Bench Card 508.pdf [accessed 2020-04-17]

24. Conermann T, Gosalia AR, Kabazie AJ, Moore C, Miller K, Fetsch M, et al. Utility of oral fluid in compliance monitoring of opioid medications. Pain Physician 2014;17(1):63-70 [FREE Full text] [Medline: 24452646]

25. United States Department of Justice. Millennium Health Agrees to Pay \$256 Million to Resolve Allegation of Unnecessary Drug and Genetic Testing and Illegal Remuneration to Physicians www. 2015 Oct 19. URL: https://www.justice.gov/opa/ pr/millennium-health-agrees-pay-256-million-resolve-allegations-unnecessary-drug-and-genetic [accessed 2020-04-17]

26. Adams NJ, Plane MB, Fleming MF, Mundt MP, Saunders LA, Stauffacher EA. Opioids and the treatment of chronic pain in a primary care sample. J Pain Symptom Manage 2001 Sep;22(3):791-796. [Medline: 11532592]

27. Butler SF, Budman SH, Fernandez K, Jamison RN. Validation of a screener and opioid assessment measure for patients with chronic pain. Pain 2004 Nov;112(1-2):65-75. [doi: 10.1016/j.pain.2004.07.026] [Medline: 15494186]

28. Butler SF, Fernandez K, Benoit C, Budman SH, Jamison RN. Validation of the revised Screener and Opioid Assessment for Patients with Pain (SOAPP-R). J Pain 2008 Apr;9(4):360-372 [FREE Full text] [doi: 10.1016/j.jpain.2007.11.014] [Medline: 18203666 ]

29. Butler SF, Budman SH, Fernandez KC, Houle B, Benoit C, Katz N, et al. Development and validation of the Current Opioid Misuse Measure. Pain 2007 Jul;130(1-2):144-156 [FREE Full text] [doi: 10.1016/j.pain.2007.01.014] [Medline: 17493754]

30. Coambs RB, Jarry JL, Santhiapillai AC, Abrahamsohn RV, Atance CM. The SISAP: A New Screening Instrument for Identifying Potential Opioid Abusers in the Management of Chronic Nonmalignant Pain Within General Medical Practice. Pain Res Manag 1996;1(3):155-162. [doi: 10.1155/1996/391248]

31. Webster LR, Webster RM. Predicting aberrant behaviors in opioid-treated patients: preliminary validation of the Opioid Risk Tool. Pain Med 2005;6(6):432-442. [doi: 10.1111/j.1526-4637.2005.00072.x] [Medline: 16336480]

32. Belgrade MJ, Schamber CD, Lindgren BR. The DIRE score: predicting outcomes of opioid prescribing for chronic pain. J Pain 2006 Sep;7(9):671-681 [FREE Full text] [doi: 10.1016/j.jpain.2006.03.001] [Medline: 16942953]

33. Fishbain DA, Rosomoff HL, Rosomoff RS. Drug abuse, dependence, and addiction in chronic pain patients. Clin J Pain 1992 Jun;8(2):77-85. [Medline: 1633386$]$

34. Morasco BJ, Peters D, Krebs EE, Kovas AE, Hart K, Dobscha SK. Predictors of urine drug testing for patients with chronic pain: Results from a national cohort of U.S. veterans. Subst Abus 2016;37(1):82-87. [doi: 10.1080/08897077.2015.1110742] [Medline: 26516794]

35. Matteliano D, Chang Y. Describing prescription opioid adherence among individuals with chronic pain using urine drug testing. Pain Manag Nurs 2015 Mar;16(1):51-59. [doi: 10.1016/j.pmn.2014.04.001] [Medline: 24939349]

36. Couto JE, Romney MC, Leider HL, Sharma S, Goldfarb NI. High rates of inappropriate drug use in the chronic pain population. Popul Health Manag 2009 Aug;12(4):185-190. [doi: 10.1089/pop.2009.0015] [Medline: 19663620]

37. Reisfield GM, Wasan AD, Jamison RN. The prevalence and significance of cannabis use in patients prescribed chronic opioid therapy: a review of the extant literature. Pain Med 2009 Nov;10(8):1434-1441. [doi:

10.1111/j.1526-4637.2009.00726.x] [Medline: 19793342]

38. Lynskey MT, Heath AC, Bucholz KK, Slutske WS, Madden PAF, Nelson EC, et al. Escalation of drug use in early-onset cannabis users vs co-twin controls. JAMA 2003;289(4):427-433. [doi: 10.1001/jama.289.4.427] [Medline: 12533121] 
39. Okaneku J, Vearrier D, McKeever RG, LaSala GS, Greenberg MI. Change in perceived risk associated with marijuana use in the United States from 2002 to 2012. Clin Toxicol 2015 Feb 03;53(3):151-155. [doi: 10.3109/15563650.2015.1004581]

40. Leafly. Qualifying Conditions for Medical Marijuana by State URL: https://www.leafly.com/news/health/ qualifying-conditions-for-medical-marijuana-by-state [accessed 2020-04-15]

41. Bonn-Miller MO, Boden MT, Bucossi MM, Babson KA. Self-reported cannabis use characteristics, patterns and helpfulness among medical cannabis users. Am J Drug Alcohol Abuse 2014 Jan;40(1):23-30. [doi: 10.3109/00952990.2013.821477] [Medline: 24205805]

42. Shah A, Hayes CJ, Lakkad M, Martin BC. Impact of Medical Marijuana Legalization on Opioid Use, Chronic Opioid Use, and High-risk Opioid Use. J Gen Intern Med 2019 Aug;34(8):1419-1426. [doi: 10.1007/s11606-018-4782-2] [Medline: 30684198]

43. Olfson M, Wall MM, Liu S, Blanco C. Cannabis Use and Risk of Prescription Opioid Use Disorder in the United States. Am J Psychiatry 2018 Jan 01;175(1):47-53 [FREE Full text] [doi: 10.1176/appi.ajp.2017.17040413] [Medline: 28946762]

44. Shi Y, Liang D, Bao Y, An R, Wallace MS, Grant I. Recreational marijuana legalization and prescription opioids received by Medicaid enrollees. Drug Alcohol Depend 2019 Jan 01;194:13-19 [FREE Full text] [doi: 10.1016/j.drugalcdep.2018.09.016] [Medline: 30390550]

\author{
Abbreviations \\ CDC: Centers for Disease Control and Prevention \\ COAT: chronic opioid analgesic therapy \\ GEE: generalized estimating equations \\ OR: odds ratio \\ THC: tetrahydrocannabinol \\ UDT: urine drug testing
}

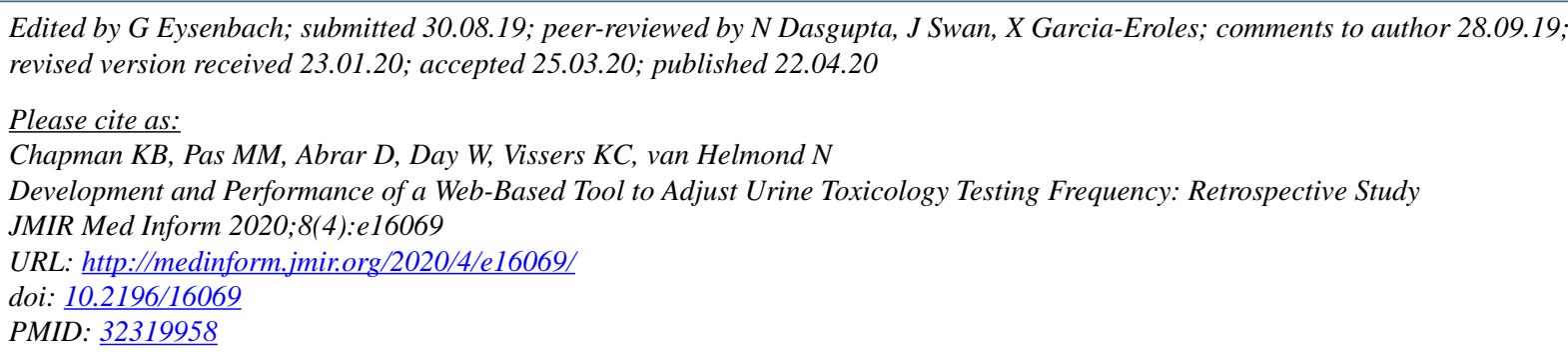

CKenneth B Chapman, Martijn M Pas, Diana Abrar, Wesley Day, Kris C Vissers, Noud van Helmond. Originally published in JMIR Medical Informatics (http://medinform.jmir.org), 22.04.2020. This is an open-access article distributed under the terms of the Creative Commons Attribution License (https://creativecommons.org/licenses/by/4.0/), which permits unrestricted use, distribution, and reproduction in any medium, provided the original work, first published in JMIR Medical Informatics, is properly cited. The complete bibliographic information, a link to the original publication on http://medinform.jmir.org/, as well as this copyright and license information must be included. 